\title{
Ventilatory Response to a Hyperoxic Test Is Related to the Frequency of Short Apneic Episodes in Late Preterm Neonates
}

\author{
VIRGINIE CARDOT, KAREN CHARDON, PIERRE TOURNEUX, SANDRINE MICALLEF, ERWAN STÉPHAN, ANDRÉ LÉKÉ, \\ VÉRONIQUE BACH, JEAN-PIERRE LIBERT, AND FRÉDÉRIC TELLIEZ
}

\author{
Dysrégulations Métaboliques Acquises et Génétiques (EA3901) [V.C., K.C., P.T., E.S., A.L., V.B., J.-P.L., F.T.], Medical Faculty, \\ University of Picardy, 80036 Amiens, France; Neonatal Department [P.T., A.L.], University Hospital, 80054 Amiens, France; \\ Toxi-Ineris [S.M.], Parc Alata, BP2, 60550 Verneuil en Halatte, France
}

\begin{abstract}
Chemoreception is frequently involved in the processes underlying apnea in premature infants. Apnea could result from a decrease in carotid body effectiveness. However, increased carotid body activity could also initiate apnea through hypocapnia following hyperventilation when the receptors are stimulated. The aim of this study was to analyze the relationship between carotid body effectiveness and short apneic episodes in older preterm neonates. Carotid body effectiveness was assessed at thermoneutrality in 36 premature neonates $(2.07 \pm 0.26 \mathrm{~kg})$ by performing a $30-\mathrm{s}$ hyperoxic test during sleep, the oxygen inhalation involving a ventilation decrease. Blood $\mathrm{O}_{2}$ saturation $\left(\mathrm{Sp}_{\mathrm{o} 2}\right)$ and ventilatory parameters were monitored before and during the hyperoxic test. Short episodes of apnea (frequency and mean duration) were recorded during the morning's 3-h interfeeding interval. Pretest $\mathrm{Sp}_{\mathrm{o} 2}$ was not related to any of the measured respiratory parameters. A higher frequency of short apneic episodes was linked to a greater ventilation decrease in response to the hyperoxic test $(\rho=-0.32 ; p=0.01)$. Increased carotid body response is correlated with greater apneic episodes frequency, even in the absence of concomitant oxygen desaturation. Fetal or early postnatal hypoxemia could have increased peripheral chemoreceptor activity, which could initiate a "overshoot/ undershoot" situation, which in turn could induce a critical $\mathrm{P}_{\mathrm{o} 2} / \mathrm{P}_{\mathrm{CO} 2}$ combination and apnea. (Pediatr Res 62: 591-596, 2007)
\end{abstract}

$\mathrm{S}^{\mathrm{h}}$ hort apneic episodes [defined as a respiratory pause of at least $3 \mathrm{~s}(1,2)]$ are common respiratory events in premature neonates, with an incidence of $25 \%$ in infants weighing $<2500$ g at birth and $84 \%$ in those weighing $<1000 \mathrm{~g}(3)$.

After birth, apnea frequency decreases progressively once chemoreception control is sufficiently developed to initiate the appropriate ventilatory responses to changes in arterial blood gas status (3-6). Chemoreception control is carried out by central and peripheral chemoreceptors that differ in their anatomical location and type of stimulation: peripheral chemoreceptors (mainly carotid bodies) are sensitive to variations in the levels of $\mathrm{O}_{2}$ and (to a lesser extent) $\mathrm{CO}_{2}$, whereas

Received January 3, 2007; accepted June 20, 2007.

Correspondence: Virginie Cardot, D.M.A.G., Medical Faculty, University of Picardy, 3 Rue des Louvels, 80036 Amiens, France; e-mail: virginie.cardot@etud.u-picardie.fr

This work was funded by grants from the Regional Council of Picardy and the French Ministry of Research. central chemoreceptors are especially sensitive to variations in $\mathrm{CO}_{2}$ and $\mathrm{pH}$.

It is accepted that abnormal functioning of the peripheral chemoreceptors can promote apnea even though the mechanism underlying this altered chemoreceptor activity is still subject to much debate. Provision of oxygen to infants suffering from bronchopulmonary dysplasia delays the peripheral chemoreceptor response and might induce more apnea (7). In preterm neonates, an increase in the chemoreceptor gain during the postnatal period has also been suggested. The latter can initiate an "overshoot/undershoot" situation: the apnea results from a central depression in inspiratory motor drive, which is mainly due to hypocapnia. This concept has been described in adult dogs to explain periodic breathing (8) and extended to the newborn lamb (9), but physiologic mechanisms of periodic breathing and apnea are not clear (10).

In preterm neonates, with advancing age, the chemoreceptor gain increases $(4,5)$, whereas the apneic threshold for $\mathrm{CO}_{2}$ arterial pressure decreases (11). Mild hypoxemia can increase ventilation and produce apnea (10). Nock et al. (12) concluded that short periods of hypoxia that can occur with repetitive apnea could alter carotid body activity.

Many studies have focused on pathologic apnea (duration $>15 \mathrm{~s})$. There is a need to study the basic physiologic mechanisms underlying short apneic episodes $(3 \mathrm{~s})$, which can be defined as nonpathologic events in preterm infants who have never been exposed to hyperoxia or identified as being hypoxic. The increased carotid body activity in preterm neonates may be one of the factors contributing to the vulnerability of some children to sudden infant death syndrome (13). Hence, it may be necessary to seek mechanisms for ending these events.

The aims of the present study were to test the hypotheses whereby (1) short apneic episode frequency and duration would be correlated with the magnitude of carotid body activity in sleeping premature neonates and (2) this correlation would not depend on whether brief apneas were accompanied by spontaneous blood $\mathrm{O}_{2}$ desaturation. A hyperoxic test

Abbreviations: AS, active sleep $f$, respiratory frequency (breaths $\cdot \min ^{-1}$ ); QS, quiet sleep; RT, reaction time (s); $\mathbf{S p o}_{2}$, blood $\mathrm{O}_{2}$ saturation $(\%) ; \dot{V}_{\mathrm{E}}$, minute ventilation $\left(\mathrm{mL} \cdot \mathrm{min}^{-1} \cdot \mathrm{kg}^{-1}\right) ; \mathbf{V}_{\mathbf{T}}$, tidal volume $\left(\mathrm{mL} \cdot \mathrm{kg}^{-1}\right)$ 
Table 1. Physical parameters (mean $\pm 1 S D$ ) for the 36 premature neonates

\begin{tabular}{lc}
\hline Gestational age $(\mathrm{wk})$ & $30.5 \pm 1.9$ \\
\hline Birth weight $(\mathrm{kg})$ & $1.38 \pm 0.33$ \\
Postnatal age $(\mathrm{d})$ & $38 \pm 15$ \\
Study body weight $(\mathrm{kg})$ & $2.07 \pm 0.26$ \\
\hline
\end{tabular}

(which suppresses peripheral chemoreceptor activity) was used to assess the effectiveness of these receptors.

\section{MATERIALS AND METHODS}

Subjects. Thirty-six healthy premature neonates (Table 1) were enrolled after their parents were informed of the protocol and gave their written consent. The protocol was approved by the Picardy Regional Ethics Committee. None of the neonates suffered from neurologic or cardiac disorders or from intrauterine growth retardation, and none were diagnosed hypoxic or had undergone oxygen therapy. Caffeine had been administered to 13 infants as therapy for apnea, but no studied infant had received caffeine for at least $5 \mathrm{~d}$ before the study.

Methods. The day before the experiment, the neonate was placed in the supine position in a closed, convectively heated incubator (Médipréma ISIS, Chambray-les-Tours, France) in which body and air temperatures were continuously recorded. The room's air temperature was kept constant at $22^{\circ} \mathrm{C}$. The air humidity was $1.01-1.03 \mathrm{kPa}$, and the air velocity was set to 0.01 $\mathrm{m} \cdot \mathrm{s}^{-1}$.

Recordings were performed during a 3-h morning nap after a feed. The incubator air temperature was continuously measured by thermocouples (type $\mathrm{K}$, accuracy $\pm 0.10^{\circ} \mathrm{C}$; Bioblock, Illkirch, France) placed $10 \mathrm{~cm}$ below the center of the incubator top. This temperature was adjusted using a servocontrolled, skin temperature time-derivative heating system that allows the air temperature to reach a level corresponding to individual thermoneutrality for each neonate (14). Hence, the average equilibrium temperature corresponds to an optimal thermal environment, close to the recommended air temperature $(15,16)$. Maintenance of this temperature ensured that temperature-induced alterations in ventilation were avoided $(1,2,17)$. Skin surface (cheek and abdominal) temperatures were measured using thermocouples. Rectal temperature was monitored by a thermistor probe (type YSI 402, accuracy \pm $0.10^{\circ} \mathrm{C}$; Bioblock) inserted $2 \mathrm{~cm}$ past the anal sphincter. All temperatures $\left({ }^{\circ} \mathrm{C}\right)$ were continuously sampled at 10 -s intervals.

Active sleep (AS) and quiet sleep (QS) were scored online based on the following recordings (18): two electroencephalogram leads, eye and body movements, electrocardiogram (standard leads), and respiratory signals. Breathing movements were measured by thoracic impedance (Alice 4, Respironics, Nantes, France). $\mathrm{SpO}_{2}$ was monitored by a pulse oximeter (Oximax MAX-N, sampling of 1s; Tyco Healthcare group LP, Nellcor Puritan Bennett Division, Pleasanton, CA).

Peripheral chemoreceptor activity is typically assessed by the immediate fall in minute ventilation $\left(\dot{V}_{\mathrm{E}}, \%\right)$ after a 30 -s hyperoxic test consisting of inhalation of a hyperoxic gas $\left(100 \% \mathrm{O}_{2}\right)(19)$. This drop suppresses peripheral chemoreceptor inputs (i.e. physiologic chemodenervation) and thus reflects the strength of the peripheral chemoreceptor drive during resting ventilation.

The hyperoxic test was performed with a face mask attached to a pneumotachograph (Statice Santé, Besançon, France) gently placed over the infant's face. This was done by the same investigator in all neonates. Care was taken to avoid leakage. The face mask application is known to disrupt the breathing pattern by increasing minute ventilation and tidal volume (20), but these effects are transient [10-40 s (21)]. Consequently, we started our tests at least $1 \mathrm{~min}$ after the face mask application. A previous study showed that the variability from one individual to another may be a limitation (22). However, it showed also that these hyperoxic tests were reproducible with small individual coefficients of variation (23\%). This study showed also that the hyperoxic tests modified neither the ventilatory response of the neonates nor the state of alertness (22). The pneumotachograph response was linear up to a rate of $500 \mathrm{~mL} \cdot \mathrm{s}^{-1}$. A two-way computer-controlled electric valve attached to the pneumotachograph could be opened either to a bag containing $100 \% \mathrm{O}_{2}$ (test period) or to the incubator air (pretest period) $(22,23)$. The response time of the valve was $10 \mathrm{~ms}$ providing a rapid square-wave increase in $\mathrm{O}_{2}$ for 30-s and rapid return to room air. The apparatus had a flow resistance of $0.3 \mathrm{kPa} \cdot 1^{-1} \cdot \mathrm{s}^{-1}$ and a total instrumental dead space of $2.5 \mathrm{~mL}$ $(22,23)$.
The hyperoxic test was performed once during well-established episodes of both AS and QS. It consisted of two 30-s periods: the pretest period, the neonate breathes air from the incubator, and the test period, the computer detects the last normoxic expiration and switches the valve when the flow direction changes (i.e. at the inspiration-expiration transition), thus starting the hyperoxic test. Throughout the hyperoxic period, the infant inspires $100 \%$ $\mathrm{O}_{2}$ from the bag and expires into the incubator.

Hyperoxic test. The $\mathrm{Spo}_{2}$ value (\%) was averaged for the 30-s period before placement of the mask on the neonate's face and during the pretest period. Because there was no difference between these two $\mathrm{Spo}_{2}$ values $(p=$ 0.349 ), the pretest $\mathrm{Spo}_{2}$ value was considered as the $\mathrm{Spo}_{2} . \mathrm{Spo}_{2}$ was also measured during the hyperoxic test itself.

For each hyperoxic test, the respiratory flow was integrated by the pneumotachograph for breath-by-breath measurements of minute ventilation $\left(\dot{V}_{\mathrm{E}}, \mathrm{mL} \cdot \mathrm{min}^{-1} \cdot \mathrm{kg}^{-1}\right)$, tidal volume $\left(\mathrm{V}_{\mathrm{T}}, \mathrm{mL} \cdot \mathrm{kg}^{-1}\right)$ and respiratory frequency $\left(f\right.$, breaths $\left.\cdot \min ^{-1}\right)$. These parameters were averaged over the 30 -s pretest period.

During the hyperoxic test, breath-by-breath recorded values were averaged over a four-breath moving window $(22,23)$. These mean $\dot{V}_{\mathrm{E}}$ values were subjected to one-way analysis of variance with the moving window as the repeated factor. The $\dot{V}_{\mathrm{E}}$ response to the hyperoxic test was considered significant when the main effect of the moving sequence was significant $(p \leq$ $0.05)$. Hence, the reaction time (RT, s) was defined as the time between hyperoxia onset and the first statistically significant change in $\dot{V}_{\mathrm{E}}$ (Fig. 1). The percentage of change at RT was assessed for all respiratory parameters reported above.

Baseline 3-h period. Short apneas recorded using thoracic impedancemetry was defined as a respiratory pause lasting $>3 \mathrm{~s}(1,2)$, according to the recommendations of Gould et al. (24), who showed that apneic events as short as $2-5 \mathrm{~s}$ can be scored and can have specific effects. These brief respiratory pauses are considered as indicators of physiologic (and not pathologic) processes, with our aim being to analyze the neonate's respiratory behavior. In the present study, apneic episodes were distinguished from periodic breathing. The latter phenomenon (corresponding to regular respiration cycles interrupted by pauses) was discarded for our analysis because its mechanisms are still unclear and differ from those of apnea (9). After the manual sleep score, the different events detected by the polysomnograph (i.e. apneic episodes and desaturations) were re-examined manually to eliminate movement artifacts. Desaturation did not occur before short apneas in any of these episodes. The time during which the experimenter intervened in the incubator ( $2 \mathrm{~min}$ before, $1 \mathrm{~min}$ after, and during the hyperoxic test) was discarded from apnea analysis to reduce the procedure's potential influence. Short respiratory pauses were described in terms of frequency (apneas $\cdot \mathrm{h}^{-1}$ ) and mean duration (s). Two types of apneic episodes were considered: episodes with or without blood $\mathrm{O}_{2}$ desaturation, with the latter corresponding to a fall in $\mathrm{SpO}_{2}$ of $>5 \%$ in reference to the period before apnea (25). Sleep and apneas were scored throughout the 3-h interfeed interval. If no apneic episode occurred during the recording, the apnea frequency was set to 0 apneas $\cdot \mathrm{h}^{-1}$, and the mean duration was considered as missing values in the statistical analysis.

None of the studied parameters followed a normal distribution (as assessed by single-sample Kolmogorov-Smirnov tests). As a result, non-

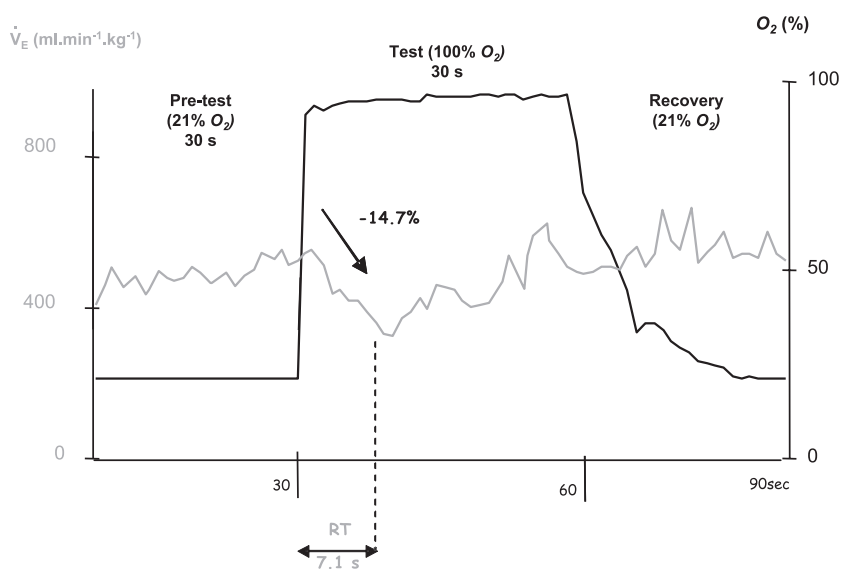

Figure 1. Example (subject 15) of the ventilatory response to a hyperoxic test and calculation of the RT (7.1 s). Pretest $\dot{V}_{\mathrm{E}},\left(\mathrm{mL} \cdot \mathrm{mix}^{-1}, \mathrm{~kg}^{-1}\right) ; \mathrm{O}_{2}$, [inspired fraction of oxygen (\%)]; $14.7 \%$, a ventilation decrease of $14.7 \%$ is observed in response to inhalation of $100 \% \mathrm{O}_{2}$. 
parametric tests were used: Wilcoxon tests to assess the influence of sleep state on the ventilatory responses, Mann-Whitney $U$ tests to analyze ventilatory responses according to the apneas prevalence, and Spearman's rank correlation $(\rho)$ to analyze relationships between these parameters.

The tests were performed separately on apneic episodes with and without blood $\mathrm{O}_{2}$ desaturation. As the two types of apnea did not show any differences for none of the parameters ( $p$ values ranging from 0.068 to 0.981 ), the data were pooled. Furthermore, and as expected, our data revealed a significant sleep state effect, but, given that the correlations between the different parameters were consistent and showed similar response patterns in both AS and QS, the recorded data were pooled for the analysis presented below.

The significance level $p$ was set to $\leq 0.05$. Data were expressed as the mean $\pm 1 \mathrm{SD}$.

\section{RESULTS}

Baseline 3-h period. At thermoneutrality, the mean equilibrium incubator temperature was $32.6 \pm 0.8^{\circ} \mathrm{C}$. The cheek skin temperature was $36.0 \pm 0.4^{\circ} \mathrm{C}$, the abdominal skin temperature was $36.8 \pm 0.3^{\circ} \mathrm{C}$, and the rectal temperature was $37.0 \pm 0.3^{\circ} \mathrm{C}$.

The mean short apnea frequency was $39.2 \pm 35.3$ apneas $\cdot \mathrm{h}^{-1}$ (AS: $52.8 \pm 35.6$ versus QS: $25.6 \pm 29.7$ apneas $\left.\cdot \mathrm{h}^{-1} ; p<0.001\right)$. The mean apneas duration was $5.5 \pm 1.3 \mathrm{~s}$ (AS: $5.3 \pm 0.8$ versus $\mathrm{QS}: 5.9 \pm 1.6 \mathrm{~s} ; p=0.050$ ). The desaturation associated to respiratory pauses was $6.8 \pm$ $1.2 \%$ on average.

Hyperoxic test. Sixty-seven hyperoxic tests were performed on the 36 neonates (AS: $n=34$; QS: $n=33$ ). All the neonates increased rapidly their $\mathrm{Spo}_{2}$ to $100 \%$ with the inhalation of hyperoxic gas.

On average, pretest $f$ was $52.9 \pm 10.1$ breaths $\cdot \min ^{-1}$ (AS: $56.8 \pm 9.8$ versus $\mathrm{QS}: 49.0 \pm 8.9$ breaths $\cdot \min ^{-1} ; p=0.002$ ) and pretest $\mathrm{V}_{\mathrm{T}}$ was $6.7 \pm 1.8 \mathrm{~mL} \cdot \mathrm{kg}^{-1}$ (AS: $6.8 \pm 1.9$ versus QS: $6.5 \pm 1.8 \mathrm{~mL} \cdot \mathrm{kg}^{-1} ; p=0.252$ ). Pretest $\dot{V}_{\mathrm{E}}$ (mean: $349.8 \pm 99.8 \mathrm{~mL} \cdot \mathrm{min}^{-1} \cdot \mathrm{kg}^{-1}$; AS: $382.0 \pm 108.9$ versus QS: $316.5 \pm 77.9 \mathrm{~mL} \cdot \mathrm{min}^{-1} \cdot \mathrm{kg}^{-1} ; p=0.009$ ) was positively correlated simultaneously with both $f$ and $\mathrm{V}_{\mathrm{T}}(f: \rho=$ $\left.0.327, p=0.010 ; \mathrm{V}_{\mathrm{T}}: \rho=0.710, p<0.001\right)$. Pretest $\dot{V}_{\mathrm{E}}$ was not correlated with frequency and mean duration of short apneas $(\rho=0.103, p=0.408$ and $\rho=-0.185, p=0.149$, respectively). Comparison of pretest $\dot{V}_{\mathrm{E}}$ between neonates with few apneas and neonates presenting many apneic episodes (the median of apnea frequency $\left(28.6\right.$ apneas $\cdot \mathrm{h}^{-1}$ ) was chosen as a limit for dividing the two groups) led to similar results $(p=0.602)$ than correlation between pretest $\dot{V}_{\mathrm{E}}$ and frequency of apneic episodes: pretest $\dot{V}_{\mathrm{E}}$ was not different according to apnea frequency. Pretest blood $\mathrm{O}_{2}$ saturation (mean: $97.7 \pm 1.3 \%$; AS: $97.7 \pm 1.4$ versus $\mathrm{QS}: 97.8 \pm 1.3 \%$; $p=0.496)$ was not correlated with frequency of apneic episodes $(\rho=-0.128, p=0.315)$, apneic episodes mean duration $(\rho=$ $-0.130, p=0.319)$ and pretest $\dot{V}_{\mathrm{E}}(\rho=-0.148, p=0.243)$.

In response to the hyperoxic test, the RT was $10.3 \pm 4.3 \mathrm{~s}$ (AS: $10.9 \pm 5.2$ versus QS: $9.7 \pm 2.9 \mathrm{~s} ; p=0.299$ ) and the ventilation decrease at the RT was $-23.84 \pm 10.89 \%$ on average (AS: $-28.76 \pm 10.85$ versus $\mathrm{QS}:-18.78 \pm 8.42 \%$; $p=0.003)$. The pretest blood $O_{2}$ saturation was not correlated with the ventilation decrease $(\rho=0.130, p=0.305)$ and the RT $(\rho=0.003, p=0.984)$.

When pretest $\dot{V}_{\mathrm{E}}$ was high, the ventilatory decrease during the hyperoxic test was more pronounced $(\rho=-0.318, p=$

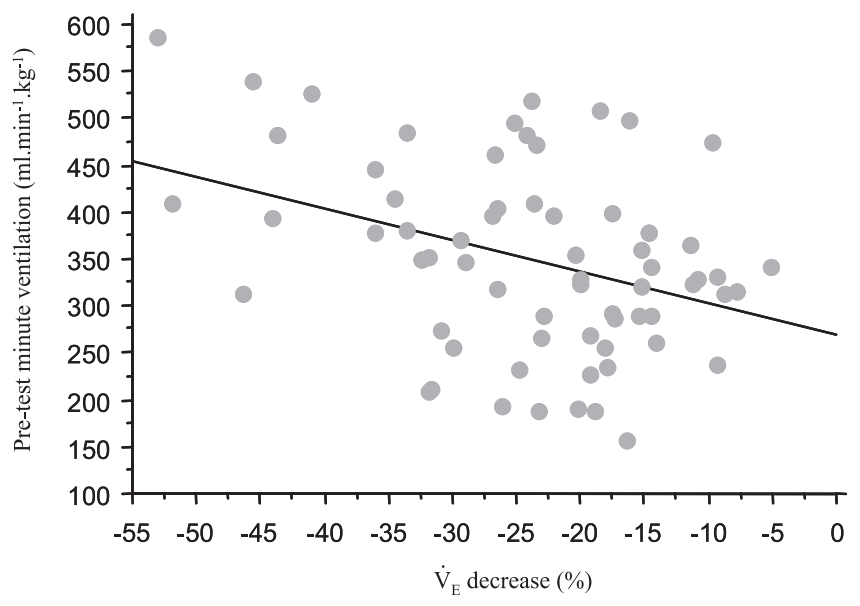

Figure 2. Relationship ( $\rho=-0.318, p=0.010$ ) between the response to the hyperoxic test, expressed in term of the percentage of ventilation decrease $\left(\dot{V}_{\mathrm{E}}\right.$, $\%)$ and the pretest $\dot{V}_{\mathrm{E}}\left(\mathrm{mL} \cdot \mathrm{min}^{-1} \cdot \mathrm{kg}^{-1}\right)$ at thermoneutrality.

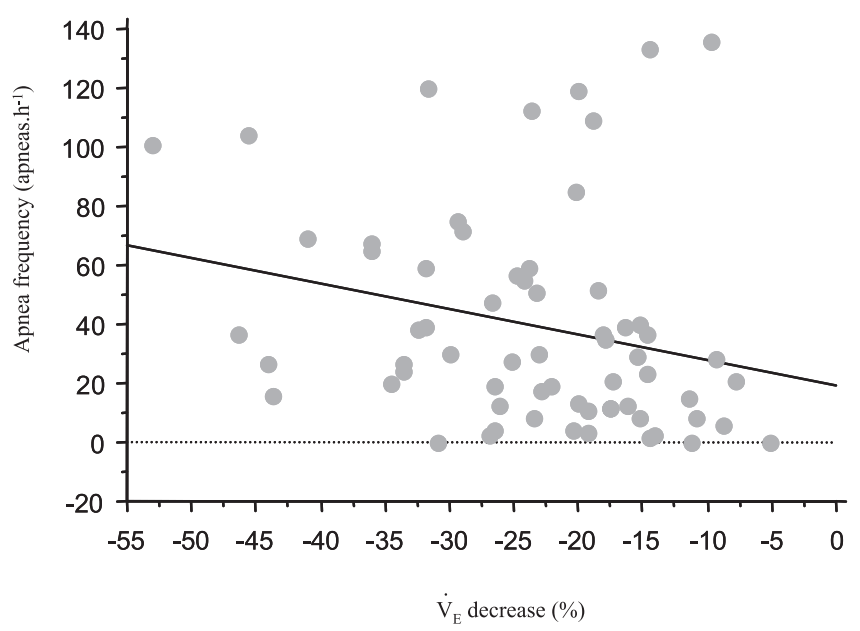

Figure 3. Relationship $(\rho=-0.320, p=0.010$ ) between the percentage of ventilation decrease $\left(\dot{V}_{\mathrm{E}}, \%\right)$ in response to the hyperoxic test and the apnea frequency (apneas $\cdot \mathrm{h}^{-1}$ ) recorded during the 3-h monitoring period at thermoneutrality.

0.010; Fig. 2). Neither pretest $\dot{V}_{\mathrm{E}}$ nor ventilation decrease to the hyperoxic test was correlated with the RT $(\rho=-0.231, p=$ $0.061 ; \rho=0.103, p=0.400$, respectively).

The most interesting result was that when the frequency of brief apneas was high, the $\dot{V}_{\mathrm{E}}$ decrease in response to the hyperoxic test was more intense ( $\rho=-0.320, p=0.010$; Fig. 3 ), with, however, a great interindividual variability: only $10.2 \%$ of the variability was explained by the correlation. In particular, in 14 of the 67 hyperoxic tests (two in AS and 12 in QS), although the ventilation decrease was marked, the associated frequency of apneic episodes was $<10$ apneas $\cdot h^{-1}$. However, a comparison of late preterm infants with few versus with frequent apnea episodes found that those with an apnea frequency greater than the median value had greater ventilatory decreases with hyperoxia $(p=0.032)$. This confirmed the relationship found when the magnitude of $\dot{V}_{\mathrm{E}}$ decrease was directly correlated with the frequency of apnea episodes. This relationship did not depend on the intermittent blood $\mathrm{O}_{2}$ desaturations (Table 2). 
Table 2. Correlations of responses to the hyperoxic test: $\dot{V}_{E}$ decrease $\left(\downarrow \dot{V}_{E}, \%\right)$ and $R T(s)$ with apnea frequency (apneas $\left.\cdot h^{-1}\right)$ and mean duration $(s)$ in accordance with the presence or absence of desaturations associated with apneas and pretest $\dot{V}_{E}\left(\mathrm{~mL} \cdot \mathrm{min}^{-1} \cdot \mathrm{kg}^{-1}\right)$

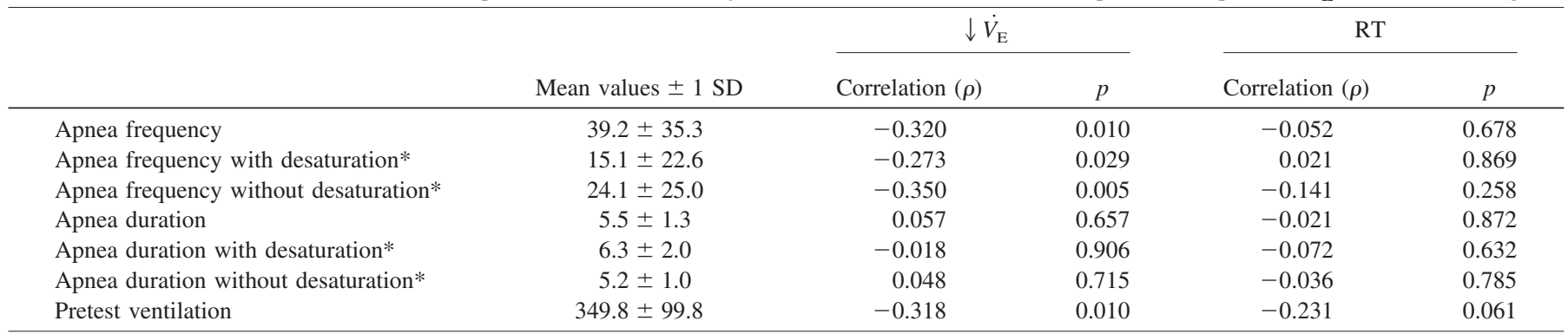

$\rho$ is the Spearman's rank correlation and $p$ values indicate significance of these correlations.

* No difference in correlations with apnea with or without desaturation was found.

\section{DISCUSSION}

The present study focuses on the mechanisms underlying the occurrence of short apneic episodes, which are considered to more or less normal for preterm neonates with a mean postmenstrual age of 35.9 wk. Short apnea episodes are common in late healthy preterm neonates, and their significance is unknown. Studies of respiratory control in late preterm infants are thus needed (11).

Although the correlation pattern for the different variables was similar in AS and QS, we found that the amplitudes of the peripheral chemoreceptor activity and the apnea frequency were higher in AS than in QS, in agreement with the findings of our previous study (17). We speculated that central control mechanisms present in AS may enhance the peripheral chemoreceptor gain in response to different challenges, which may increase the intrinsic breathing instability of AS, leading to apnea. As it has been shown elsewhere (this topic is beyond the scope of the present study), we were able to pool the sleep state data before our analysis.

In the present study, the magnitude of pretest $\dot{V}_{\mathrm{E}}$ and the pretest $\mathrm{SpO}_{2}$ value were similar to those reported in the literature (26). Neonates showed a pronounced decline in $\dot{V}_{\mathrm{E}}$ $(-25 \%)$ in response to the hyperoxic test, as reported elsewhere $(27,28)$. The ventilation decrease is detected at the RT, allowing measurement of the effectiveness of the peripheral chemoreceptors $(22,23)$.

Eichenwald et al. (29) showed that significant apnea in the most premature infants could persist over weeks or months. If the short apneic episodes observed at the time of the present study accurately reflect previous apnea patterns, then the relationship between the frequency of respiratory pauses and the ventilatory response to the hyperoxic test would appear not to depend on intermittent blood $\mathrm{O}_{2}$ desaturations. Higher chemoreceptor effectiveness is more likely to be related to fetal or early postnatal environmental, metabolic, or cardiorespiratory events, which may delay the chemoreceptor maturation necessary for resolution of persistent apneas. Changes in arterial $\mathrm{O}_{2}$ pressure levels [caused by chronic hypoxemia at birth (30) or hypoxia-induced changes in arterial $\mathrm{CO}_{2}$ (31)] may determine the sensitivity to hypoxia, which interferes with postnatal readjustment of the chemoreflex. This statement could, however, be subject to criticism as there is no evidence that the changes in transcutaneous $\mathrm{O}_{2}$ are closely related to arterial $\mathrm{O}_{2}$ pressure [with a slower response time for transcutaneous $\mathrm{O}_{2}$, in particular $\left.(7,32)\right]$, whereas another study showed that $\mathrm{PaO}_{2}$ varied broadly with $\mathrm{SpO}_{2}$ and that the latter accurately reflected the simultaneous $\mathrm{PaO}_{2}$ (33). Moreover, borderline hypoxemia could exist without a decrease in saturation (10).

Similar to Nock et al. (12), this study found that a higher frequency of apneic episodes was related to greater carotid body effectiveness and not to deficient peripheral chemoreceptor function, as is reported in infants with bronchopulmonary dysplasia (7). Nock et al. (12) suggested that increased carotid body effectiveness resulted from recurrent apneic episodes with intermittent hypoxia, but our results found no relationship between carotid body effectiveness and episodes of repeated blood $\mathrm{O}_{2}$ desaturations, which were concomitant with some apneic episodes but were minor in magnitude. Our result is consistent with the overshoot/undershoot concept proposed by Cherniack et al. (8) in adult dogs and modified by Canet et al. (9) in newborn lambs to explain periodic breathing and according to which high carotid body activity could result in apnea. Indeed, the increase in carotid body activity can promote respiratory instability and apnea when the $\mathrm{CO}_{2}$ partial pressure falls below the apneic threshold (10), thereby depressing inspiratory motor drive. This explanation is supported by studies performed in animals (34) or healthy sleeping adults (35), which have demonstrated the importance of critical $\mathrm{O}_{2}-\mathrm{CO}_{2}$ blood gas combinations with high carotid body gain in the induction of periodic breathing $(8-10,36)$. Because the critical $\mathrm{PaCO}_{2}$ thresholds that produce periodic breathing and apnea are closed (9), we can extend the assumption of an hypocapnia threshold to apnea (37).

We observed high interindividual variability, which could explain differences in the $\mathrm{CO}_{2}$ threshold for apnea. In particular, three of the 36 neonates exhibited high carotid body activity despite the total absence of short apneic episodes.

Moreover, even though that agrees with the findings of Fagenholz et al. (38), who did not observe any ventilatory difference between healthy infants and those with prolonged apnea, it could appear surprising that no correlation was observed between the frequency of apneic episodes and pretest $\dot{V}_{\mathrm{E}}$, especially if high levels of ventilation are associated 
with hypocapnia, which could then reach the apneic $\mathrm{CO}_{2}$ threshold. This phenomenon has been observed for periodic breathing in newborn lambs (9), with carotid body activity overriding the hypocapnic effects. The sole explanation relates to an upward shift in the $\mathrm{CO}_{2}$ apneic threshold, although the absence of $\mathrm{CO}_{2}$ pressure measurements makes this inconclusive.

Finally, although significant, the relationship between a ventilation decrease in response to the hyperoxic test and a higher frequency of apneic episodes only explains $10.2 \%$ of the variability in our study. Other mechanisms (especially central ones) may explain the variability by modulating chemoreceptor inputs, as reported by Xie et al. (35). In particular, the ventral medullary surface and its adjacent areas play a key integrative role in central $\mathrm{CO}_{2}$ chemosensitivity and the modulation of afferent inputs from carotid body and laryngeal afferents. Central integration could be critical in the genesis of apnea (39). This is supported by the absence of relationship between carotid body effectiveness and apnea duration. The impact of the presumed tendency to hyperventilation with subsequent hypocapnic depression of inspiratory drive could be thus limited by central means in our late preterm neonates, which results in short pauses in breathing. Therefore, significant apneas in infancy might be related to a prolongation of a high gain carotid response, a decreased respiratory center output, and a depressed ventilatory response to $\mathrm{CO}_{2}$, as shown in preterm infants with apnea $(40,41)$. Differences in the integration of the various afferent stimuli that can complement or oppose each other may thus explain part of the large interindividual variability in body carotid activity found here.

In summary, chemoreceptor effectiveness is under the control of central mechanisms; this could explain the large interindividual variability, which depends on the degree of brain maturation. In older preterm neonates, we found that an overactive carotid body might prompt unstable respiratory control that would then act as positive feedback, predisposing infants to further short apneic episodes. If prolonged later in life, the increased carotid body responsiveness in apnea-prone preterm neonates could have serious consequences in the event that central mechanisms are not mature enough to transmit a coordinated error signal to the respiratory effectors. This type of change could result in long-lasting changes, reflecting structural or functional reprogramming of the peripheral chemoreceptors, which could prevent neonates from correctly responding to a hypoxic stimulus and thus limit the infant's ability to adapt to stimulation. It would be of interest to perform further studies on infants with pathologic apneas.

Acknowledgments. The authors thank S. Delanaud, M.C. Godefroy, and the staff of the Neonatology Department for their assistance with the experiments. Their warm gratitude goes to the neonates and the parents who consented to the participation of their infant in the present study and D.
Fraser for proofreading the manuscript and English corrections.

\section{REFERENCES}

1. Bader D, Tirosh E, Hodgins H, Abend M, Cohen A 1998 Effect of increased environmental temperature on breathing patterns in preterm and term infants. J Perinatol 18:5-8

2. Berterottière D, D'Allest AM, Dehan M, Gaultier C 1990 Effects of increase in body temperature on the breathing pattern in premature infants. J Dev Physiol 13:303-308

3. Miller MJ, Martin RJ 1998 Pathophysiology of apnea of prematurity. I: Polin RA, Fox WW, Abman SH (eds) Fetal and Neonatal Physiology, Philadelphia, pp 1129-1143.

4. Girard F, Lacaisse A, Dejours P 1960 [Ventilatory O2 stimulus in the neonatal period in man.]. J Physiol (Paris) 52:108-109

5. Hertzberg T, Lagercrantz H 1987 Postnatal sensitivity of the peripheral chemoreceptors in newborn infants. Arch Dis Child 62:1238-1241

6. Jansen AH, Ioffe S, Russell BJ, Chernick V 1981 Effect of carotid chemoreceptor denervation on breathing in utero and after birth. J Appl Physiol 51:630-633

7. Katz-Salamon M, Jonsson B, Lagercrantz H 1995 Blunted peripheral chemoreceptor response to hyperoxia in a group of infants with bronchopulmonary dysplasia. Pediatr Pulmonol 20:101-106

8. Cherniack NS, Longobardo GS, Levine OR, Mellins R, Fishman AP 1966 Periodic breathing in dogs. J Appl Physiol 21:1847-1854

9. Canet E, Praud JP, Bureau MA 1997 Periodic breathing induced on demand in awake newborn lamb. J Appl Physiol 82:607-612

10. Al-Matary A, Kutbi I, Qurashi M, Khalil M, Alvaro R, Kwiatkowski K, Cates D, Rigatto H 2004 Increased peripheral chemoreceptor activity may be critical in destabilizing breathing in neonates. Semin Perinatol 28:264-272

11. Darnall RA, Ariagno RL, Kinney HC 2006 The late preterm infant and the control of breathing, sleep, and brainstem development: a review. Clin Perinatol 33:883-914

12. Nock ML, Difiore JM, Arko MK, Martin RJ 2004 Relationship of the ventilatory response to hypoxia with neonatal apnea in preterm infants. J Pediatr 144:291295

13. Gaultier C 2001 Abnormalities of the chemical control of breathing: clinical correlates in infants and children. Pediatr Pulmonol 23:114-117

14. Telliez F, Bach V, Delanaud S, Bouferrache B, Krim G, Libert JP 1997 Skin derivative control of thermal environment in a closed incubator. Med Biol Eng Comput 35:521-527

15. Hey EN 1971 The care of babies in incubators. In: Gairdner D, Hull D (eds) Recent Advances in Pediatrics. Churchill, London

16. Sauer PJ, Dane HJ, Visser HK 1984 New standards for neutral thermal environment of healthy very low birthweight infants in week one of life. Arch Dis Child 59:18-22

17. Chardon K, Telliez F, Bach V, Leke A, Delanaud S, Bouferrache B, Libert JP, Gaultier C 2004 Effects of warm and cool thermal conditions on ventilatory responses to hyperoxic test in neonates. Respir Physiol Neurobiol 140:145153

18. Curzi-Dascalova L, Peirano P, Silvestri L, Korn G 1985 [Sleep organization in normal premature newborn infants. Polygraphic study]. Rev Electroencephalogr Neurophysiol Clin 15:237-242

19. Dejours P 1962 Chemoreflexes in breathing. Physiol Rev 42:335-358

20. Fleming PJ, Levine MR, Goncalves A 1982 Changes in respiratory pattern resulting from the use of a facemask to record respiration in newborn infants. Pediatr Res $16: 1031-1034$

21. Katz-Salamon M, Hertzberg T, Lagercrantz $\mathrm{H} 1991 \mathrm{CO}_{2}$-sensitivity in newborn and young infants tested by the rebreathing method. Methodological aspects. Biol Neonate 59:126-132

22. Bouferrache B, Filtchev S, Leke A, Marbaix-Li Q, Freville M, Gaultier C 2000 The hyperoxic test in infants reinvestigated. Am J Respir Crit Care Med 161:160-165

23. Bouferrache B, Filtchev S, Leke A, Freville M, Gallego J, Gaultier C 2002 Comparison of the hyperoxic test and the alternate breath test in infants. Am J Respir Crit Care Med 165:206-210

24. Gould JB, Lee AF, James O, Sander L, Teager H, Fineberg N 1977 The sleep state characteristics of apnea during infancy. Pediatrics 59:182-194

25. 1996 Standards and indications for cardiopulmonary sleep studies in children. American Thoracic Society. Am J Respir Crit Care Med 153:866-878.

26. Gaultier C 1995 Cardiorespiratory adaptation during sleep in infants and children. Pediatr Pulmonol 19:105-117

27. Chardon K, Bach V, Telliez F, Cardot V, Tourneux P, Leke A, Libert JP 2004 Effect of caffeine on peripheral chemoreceptor activity in premature neonates: interaction with sleep stages. J Appl Physiol 96:2161-2166

28. Rigatto H, Kalapesi Z, Leahy FN, Durand M, MacCallum M, Cates D 1982 Ventilatory response to $100 \%$ and $15 \% \mathrm{O}_{2}$ during wakefulness and sleep in preterm infants. Early Hum Dev 7:1-10

29. Eichenwald EC, Aina A, Stark AR 1997 Apnea frequently persists beyond term gestation in infants delivered at 24 to 28 weeks. Pediatrics 100:354-359

30. Hanson MA, Kumar P, Williams BA 1989 The effect of chronic hypoxia upon the development of respiratory chemoreflexes in the newborn kitten. J Physiol 411:563574 
31. Hertzberg T, Hellstrom S, Holgert H, Lagercrantz H, Pequignot JM 1992 Ventilatory response to hyperoxia in newborn rats born in hypoxia-possible relationship to carotid body dopamine. J Physiol 456:645-654

32. Katz-Salamon M 2004 Delayed chemoreceptor responses in infants with apnoea. Arch Dis Child 89:261-266

33. Hay WW Jr, Brockway JM, Eyzaguirre M 1989 Neonatal pulse oximetry: accuracy and reliability. Pediatrics 83:717-722

34. Nakayama H, Smith CA, Rodman JR, Skatrud JB, Dempsey JA 2003 Carotid body denervation eliminates apnea in response to transient hypocapnia. J Appl Physiol 94:155-164

35. Xie A, Skatrud JB, Puleo DS, Dempsey JA 2006 Influence of arterial $\mathrm{O}_{2}$ on the susceptibility to posthyperventilation apnea during sleep. J Appl Physiol 100:171177
36. Bradley TD 2002 Crossing the threshold: implications for central sleep apnea. Am J Respir Crit Care Med 165:1203-1204

37. Lahiri S, Mokashi A, Delaney RG, Fishman AP 1978 Arterial $\mathrm{PO}_{2}$ and $\mathrm{PCO}_{2}$ stimulus threshold for carotid chemoreceptors and breathing. Respir Physiol 34:359-375

38. Fagenholz SA, O'Connell K, Shannon DC 1976 Chemoreceptor function and sleep state in apnea. Pediatrics 58:31-36

39. Praud JP, Canet E, Bureau MA 1992 Chemoreceptor and vagal influences on thyroarytenoid muscle activity in awake lambs during hypoxia. J Appl Physiol 72:962-969

40. Gerhardt T, Bancalari E 1984 Apnea of prematurity: I. Lung function and regulation of breathing. Pediatrics 74:58-62

41. Gerhardt T, Bancalari E 1984 Apnea of prematurity: II. Respiratory reflexes. Pediatrics 74:63-66 